\title{
Proposed Design Graphs of Geotextile Reinforcement on Soft Clay under Various Field Conditions
}

\author{
Sari, P.T.K. ${ }^{*}$, Lastiasih, Y. ${ }^{1}$, and Sugiarto ${ }^{2}$
}

\begin{abstract}
This paper describes the behavior of reinforced embankments constructed on soft clay subgrade with varying compressible depths, embankment slopes and embankment heights. The stability of the embankment is evaluated using the Bishop method. The resistance moment and the numbers of geotextiles required are examined. It is shown that varying the subgrade and embankment can significantly affect the embankment stability and also the number of reinforcements. It requires a lot of time to design embankment reinforcements, especially when the length of the embankment is tens of kilometers. The main aim of this study is to develop graphs to assist in designing the number of geotextile reinforcements. This paper proposes design graphs to support engineers and designers to determine the required geotextile reinforcements for embankments.
\end{abstract}

Keywords: Bishop method; geotextile reinforcement; limit equilibrium; slope stability.

\section{Introduction}

The construction of road and bridge infrastructure has increased markedly in Indonesia. A growing number of infrastructure facilities need to be constructed on less stable and secure areas. It is inevitable that roads might be constructed in areas that have relatively soft subgrade, causing a tendency toward instability. In addition, to avoid flood water levels and to adjust to the topography, road construction is often carried out on high embankments. The construction of roads with relatively high embankments on soft soil subgrade can certainly raise some problems related to the stability of the road embankment.

The problem that often arises when constructing roads on high embankments and on soft soil is stability against landslide. The performance of embankments constructed on soft clays has been studied by many researches [1-8]. Some studies have been conducted to determine embankment conditions in the field by analyzing the test results of geotechnical instruments. Previous studies have also been conducted to determine the characteristics of geosynthetics installed as reinforcement for embankments. The analysis shows that the use of geosynthetics can improve the stability of embankments.

${ }^{1}$ Civil Engineering Department, Institut Teknologi Sepuluh Nopember, Surabaya 60111, INDONESIA.

${ }^{2}$ Civil Engineering Department, Bakrie University, Jakarta, INDONESIA.

*Corresponding author; e-mail: tantrigeoteknik@gmail.com

Note: Discussion is expected before November $1^{\text {st }}, 2016$, and will be published in the "Civil Engineering Dimension" volume 19, number 1, March 2017.

Received 07 July 2016; revised 21 August 2016; accepted 26 August 2016.
The use of geosynthetics as one method of road embankment reinforcement is already developed. Usually, geotextile, which is one type of geosynthetic, is used to reinforce road embankments built on soft soil foundations. Geosynthetic reinforcement has been widely used to improve the stability of embankments on soft clay soils [9-16]. Geotextile layers increase embankment stability by virtue of two primary functions: as tensile reinforcement and as a drainage element to reduce pore pressure. The properties and characteristics of reinforced embankments constructed on soft ground are already widely understood and developed by researchers and implementers in the field.

Road construction is often conducted for many kilometers with each area having a different embankment height. In addition, the subgrade under the embankment also has different characteristics. With vast variation in the height of embankments and types of subgrade, designers might feel overwhelmed when having to design the reinforcement. Calculation of the number of geotextile reinforcements is usually done piece by piece, in accordance with the variation of height of the embankment and the type of subgrade underneath, which is a very time-consuming exercise. Designers usually have only very limited time, on the other hand the construction process should be implemented immediately.

The main purpose of this study is to develop graphs to assist engineers or designers to design the required number of geotextile reinforcements for road embankments located on soft clay under various field conditions, to accelerate the design process. 


\section{Method}

Variables considered in this study include the height of road embankment, the depth of soft clay soil, and the characteristics of the subgrade. Data were collected from three construction sites or projects in Java Island, Indonesia:

- Ngawi Kertosono Highway Road Construction Project, Package 2 (STA $111+250$ to STA $118+$ 700);

- Porong Gempol Toll Road Construction Project; and

- Surabaya Mojokerto Highway Road Construction Project.

Data taken from the three different locations are expected to represent the variety of soft soil characteristics, particular to Java Island.

The height of road embankments at Ngawi Kertosono Highway Road Construction Project varies from 2-7.5 meters. For the Porong Gempol Toll Road project, the variation in embankment height is $2-7.8$ meters, and for the Surabaya Mojokerto project the height varies from 2-5 meters. The type of subgrade in these three locations is predominantly soft clay, with compressible soil depth between 4-20 meters.

Based on the above mentioned variations, the stability of the road embankments and the required number of geotextile reinforcements, respectively, were analyzed in several groups:

- the heights of embankment are of two, four, six, and eight meters;

- the slopes of the embankment are $1: 1,1: 2$, and 1 : 3 ;

- the depths of soft soil are 5, 10, 15, and 20 meters;

- the characteristics of subgrade soil are distinguished by the degree of plasticity: low, medium, or high plasticity.

Altogether, 32 variations were analyzed. Analysis of the stability of the embankment was conducted using the Limit Equilibrium Method (LEM) with the concept of the moment equilibrium method.

This method is widely used to analyze geotechnical landslides. LEM has been developed since the early $20^{\text {th }}$ century. In 1915, Petterson presented an analysis of the stability of embankments of Stigberg Quay in Gotherberg, Sweden, using the method of vertical slices. This method was further developed by several researchers [5]. The development of computer calculations by auxiliary programs began in the 1960 s, which has made the development of mathematical formulas easier.

\section{Geotextile Design}

Allowable stress of geotextile for reinforcement construction planning is defined as the ultimate tensile strength of age appropriate construction plan divided by the reduction factor is taken into account. The allowable stress values of geotextile are in accordance with the following equation:

$\sigma_{a n}=\sigma_{c}\left(\frac{1}{f_{d}} \cdot \frac{1}{f_{e n v}} \cdot \frac{1}{f_{m}} \cdot \frac{1}{f_{c}}\right)$

where $\sigma_{\text {all }}$ is allowable stress of the geotextile, $\sigma_{c}$ is the ultimate tensile strength according to age of geotextile construction, $f_{d}$ is reduction factor for mechanical damage, fenv is reduction factor for environmental condition, $\mathrm{f}_{\mathrm{m}}$ is reduction factor for the extrapolation of data for geotextile tensile strength, and fc is a secure construction factor.

Another formulation used in the calculation of allowable stress values of geotextiles is based on the American Association of State Transportation and Highway Officials (AASHTO) [17,18]. The tensile capacity of the reinforcement determined from constant-load laboratory testing must also be adjusted using reduction factors to account for sitespecific potential load of strength due to chemical and biological degradation $\left(\mathrm{RF}_{\mathrm{d}}\right)$ and mechanical damage during installation $\left(\mathrm{RF}_{\mathrm{ID}}\right)$. The allowable tensile strength of the reinforcement $\left(\mathrm{T}_{\text {allow }}\right)$ is then calculated as:

$T_{\text {allow }}=\frac{T_{\text {ult }}}{R F}=\frac{T_{\text {ult }}}{R F_{D} x R F_{I D} x R F_{C R}}$

All reduction factors must be based on productspecific testing. In no case should values for $R F_{D}$ and $\mathrm{RF}_{\mathrm{ID}}$ be less than 1.1. In the absence of such data, AASHTO recommends that RF not less than 7 or 3.5 for permanent and temporary wall structure, respectively. The magnitude of creep reduction factor $\left(\mathrm{RF}_{\mathrm{CR}}\right)$ will vary with design life. Typically values range from 1.5-3.0, with the lowest value corresponding to the shortest lifetime. The maximum design load for a geosynthetic layer in a permanent reinforced wall application is typically reduced to a long-term allowable design load Tdes where:

$T_{\text {des }}=\frac{T_{\text {allow }}}{F S}$

Here FS is an overall factor of safety to account for uncertainty in problem geometry, soil variability, and applied loads. FS has a minimum value of 1.2. For reinforced slope, FS $=1$ since the overall factor of safety is accounted for in the stability analyses. 
This research uses a slices approach together with the assumption of a circular failure surface. The potential failure surface must also include those passing partially through the reinforced soil mass and into the soil beyond the reinforced zone as well as those completely contained by the reinforced soil zone. A solution for the factor of safety using the Bishop method of analysis is carried out using the following equation:

$F S=\left(\frac{M r}{M D}\right)_{\text {unreinforced }}+\frac{\sum T_{a \text { llow }} x R_{\mathrm{t}}}{M D}$

where $M r$ and $M D$ are the resisting and driving moments for the unreinforced slope, respectively and $R t$ is the distance between the circle center and the geotextile layer location.

The selection of geotextile for reinforcement is influenced by internal and external factors. Internal factors consist of geotextile tensile strength, extension properties (creep), geotextile structure, and resistance to environmental factors. However, not all available geotextile tensile strength can be utilized in planning and construction reinforcement. This study used a geotextile with ultimate tensile strengths equivalent to $52 \mathrm{kN} / \mathrm{m}$ and $100 \mathrm{kN} / \mathrm{m}$.

\section{Soil Profile}

Soil data used in this study are based on a ground investigation carried out at the three road projects mentioned before. The data obtained are recapitulated, and the compressible soil depth is analyzed. In the next stage, data are correlated and compared with the empirical formula to obtain data that will be entered into an auxiliary program for slope stability analyses, SLOPE/W [19]. The main data entered into SLOPE/W are the values of undrain cohesion at each layer of the subgrade. Since the subgrade soil type is predominantly clay, the friction angle value is very small and close to zero. This study used a friction angle value for subgrade $=0$. The undrain cohesion of soil subgrade is classified into three degrees of plasticity: low, medium, and high plasticity. Cohesion values at each layer of soft clay soil are shown in Table 1.

\section{Results and Discussion}

Analysis of embankment stability against sliding was carried out using the Bishop Simplification Method. Subgrade was assumed without soil improvement, such as applying prefabricated vertical drains (PVD) or any other soil improvement techniques. Therefore, calculation has been done without considering the final and initial heights of the embankment. Subgrades considered in this study were of clay soils, therefore cohesion significantly influenced embankment stability.

Table 1. Soil Subgrade Data Used in the Analysis

\begin{tabular}{cccc}
\hline $\begin{array}{c}\text { Sub-grade Layer } \\
\text { (1 meter per each } \\
\text { layer) }\end{array}$ & $\begin{array}{c}\text { Low } \\
\text { Plasticity } \\
\mathrm{Cu}(\mathrm{kPa})\end{array}$ & $\begin{array}{c}\text { Medium } \\
\text { Plasticity } \\
\mathrm{Cu}(\mathrm{kPa})\end{array}$ & $\begin{array}{c}\text { High } \\
\text { Plasticity } \\
\mathrm{Cu}(\mathrm{kPa})\end{array}$ \\
\hline Layer 1 & 7.8 & 7.7 & 7.6 \\
Layer 2 & 8.8 & 8.5 & 8.2 \\
Layer 3 & 9.8 & 9.3 & 8.8 \\
Layer 4 & 10.7 & 10.0 & 9.4 \\
Layer 5 & 11.7 & 10.8 & 9.9 \\
Layer 6 & 12.6 & 11.5 & 10.5 \\
Layer 7 & 13.5 & 12.3 & 11.0 \\
Layer 8 & 14.5 & 13.0 & 11.6 \\
Layer 9 & 15.5 & 13.8 & 12.2 \\
Layer 10 & 16.4 & 14.6 & 12.8 \\
Layer 11 & 17.4 & 15.3 & 13.3 \\
Layer 12 & 18.3 & 16.0 & 13.8 \\
Layer 13 & 19.3 & 16.8 & 14.4 \\
Layer 14 & 20.2 & 17.6 & 15.0 \\
Layer 15 & 21.2 & 18.3 & 15.6 \\
Layer 16 & 22.0 & 19.0 & 16.1 \\
Layer 17 & 23.0 & 19.8 & 16.7 \\
Layer 18 & 23.9 & 20.6 & 17.2 \\
Layer 19 & 25.0 & 21.4 & 17.8 \\
Layer 20 & 25.9 & 22.2 & 18.4 \\
\hline
\end{tabular}

\section{Stability Analysis of Embankment}

The number of reinforcements was determined by analyzing the stability of the embankment, while considering the safety factor and the resisting moment of the embankment. If the safety factor value is smaller than $1(\mathrm{SF}<1)$, then the embankment has the possibility of a landslide. The smaller the value of the safety factor, the smaller the embankment's ability to carry the load applied. This is because the resisting moment of the embankment is smaller than the driving moment.

In determining the number of geotextile reinforcements required for the embankment, the common reference used is the safety factor value. The analysis was carried out by evaluating several possibilities of landslide. The smallest value of the accepted safety factor was not chosen as the reference in this design. Instead, landslide areas that produce the number of geotextile reinforcement is used as the reference design requirement of reinforcement number, therefore a few trials are needed to obtain the most critical condition. The experiments were performed on one of the heights of the embankment and one of the main conditions of the soil subgrade in one of the variations used. One hundred eighty iterations were performed to prove that the value of the smallest safety factor is not necessarily the most critical condition for an embankment landslide. 
The total number of geotextile reinforcement required is highly dependent on the value of delta moment resistance which is the difference between the resisting moment to the driving moment. Therefore, from the analysis results, we can see that the greatest value of delta moment resistance does not necessarily generate the smallest safety factor value. In addition, it also shows that the highest number of geotextiles is not generated by the smallest value of safety factor due to the values of resisting moment and driving moment

The results of embankment stability analysis with a height of two meters showed that the embankment is quite stable against the danger of sliding. Figure 1 shows that the safety factor is greater than one so that the embankment is reasonably stable even without reinforcement. The stability of the embankment also occurs in all variations used in this study. Thus, for the two meter embankment, structurally it does not require geotextile reinforcement.

The analysis result for embankments higher than two meters showed that reinforcements are needed as support against landslide. Figure 2 shows the safety factor values and delta moment resistance for a four-meter embankment. These graphs show that the greater the slope of the embankment, the greater the value of its safety factor. The degree of plasticity of the subgrade also affects the safety factor. The higher the plasticity, the smaller the safety factor for the embankment.

This condition also occurs for embankments of six and eight meters. However, in the four-meter embankments, the depth of subgrade does not affect stability against landslide very much. This condition can be seen in the different safety factors with the different soil depths. This is because the deepest depth of landslide in the four-meter embankments is approximately 5 meters (Figure 3); therefore, a depth of 10-20 meters of soft ground does not affect the stability of the embankment.

From Figure 3, it can be seen that the depth of the soft subgrade does not impact much on the stability of the embankment and the depth of landslides area. This condition occurs as the height of the embankment is relatively low to moderate. Thus, the higher the embankment, the greater the effect of soft ground depth on the depth of landslide area.

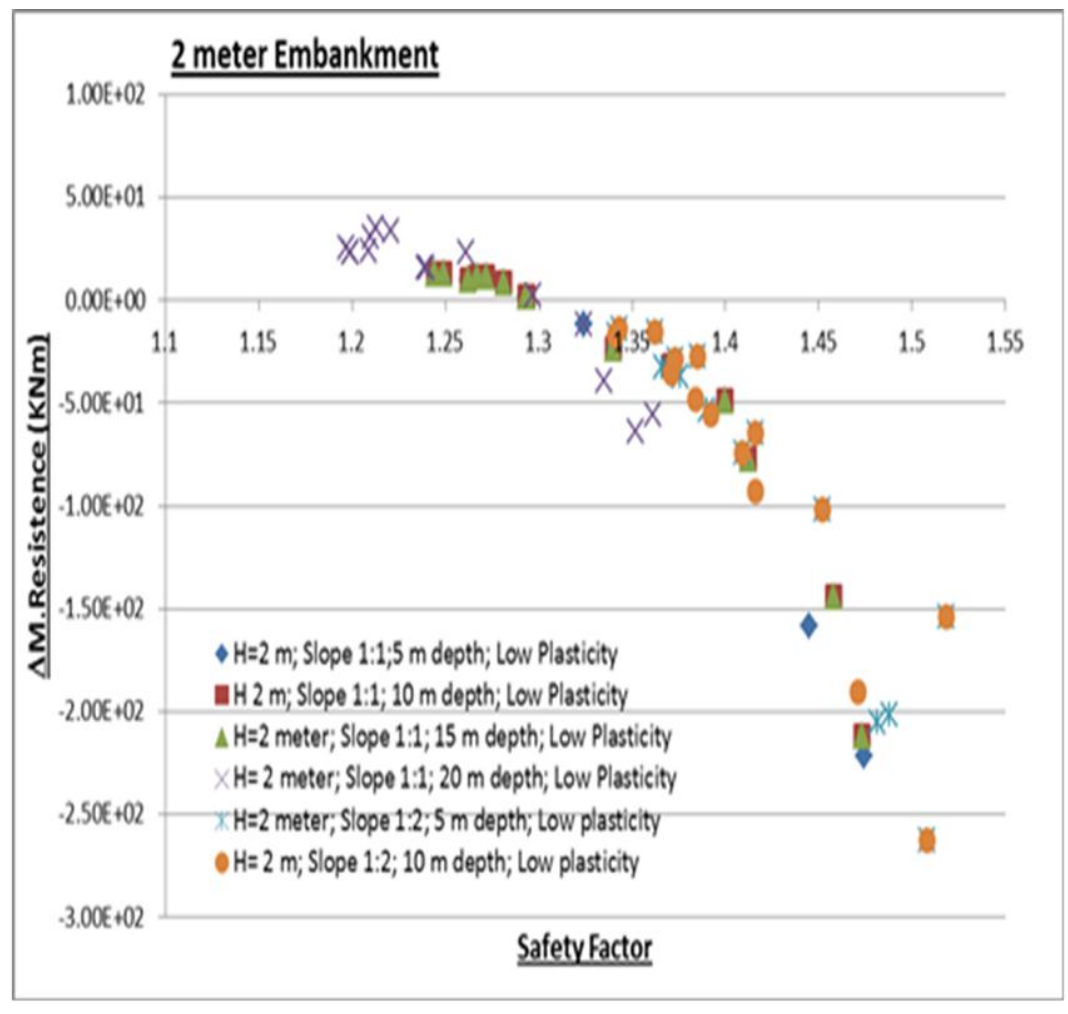

Figure 1. Safety Factor and Moment Resistance of Two-meter Embankment with Varying Conditions. 

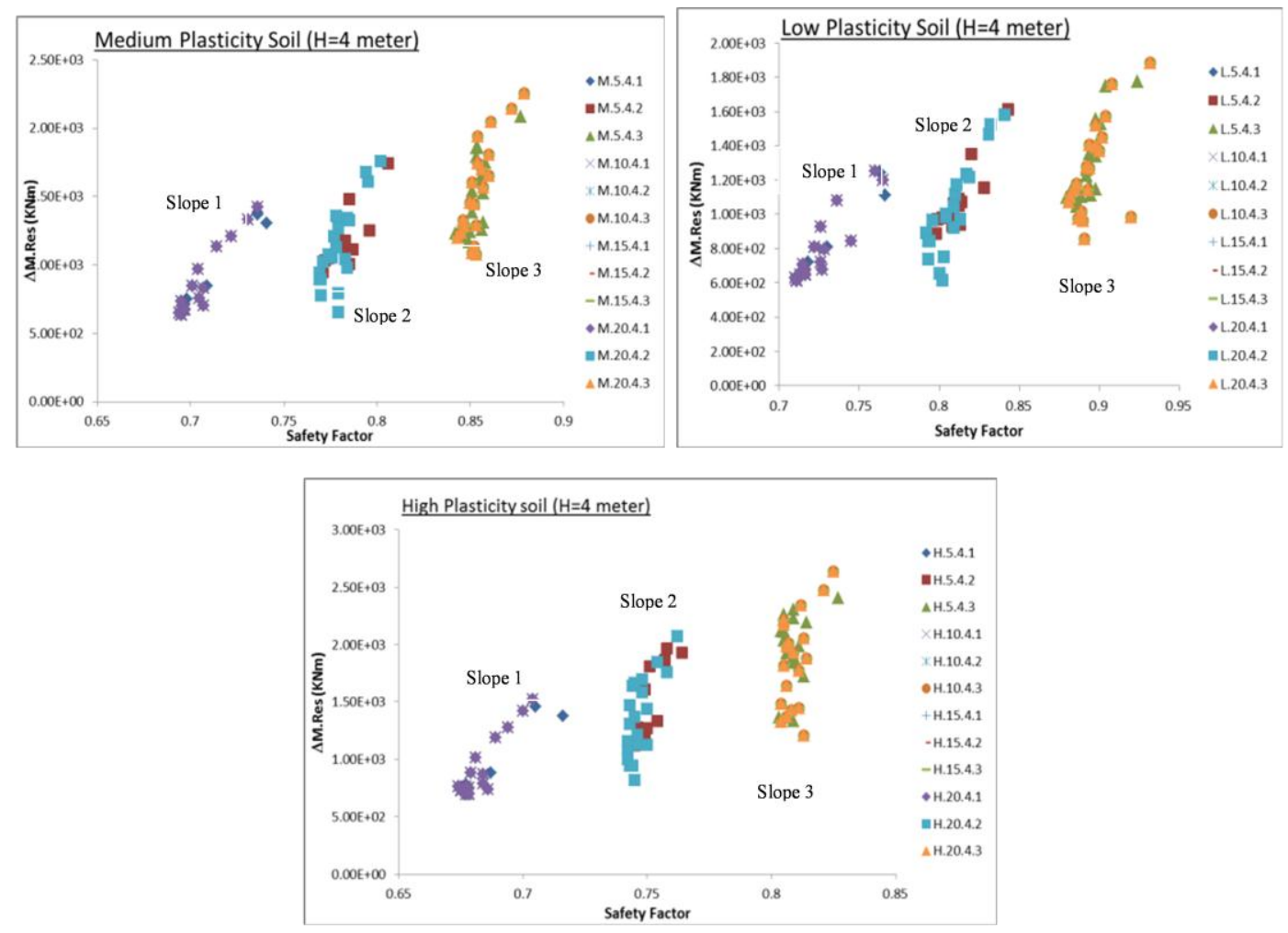

Figure 2. Safety Factor and $\Delta$ Moment Resistance of 4-meter Embankment with Varying Conditions
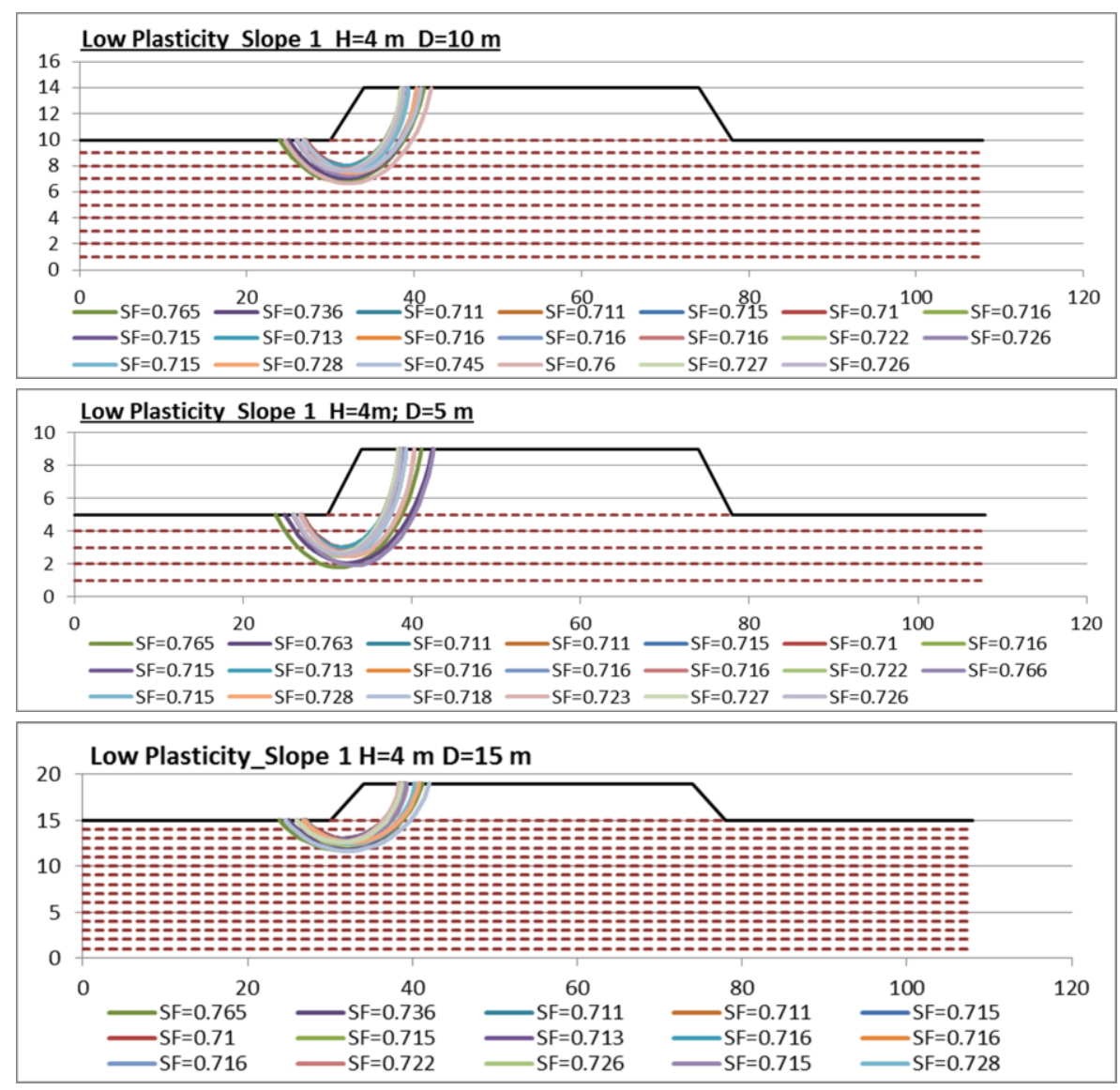

Figure 3. Landslide Depth of Four-meter Embankment with Various Depths of Soft Soil Subgrade. 
This condition can be seen in the analysis of embankment stability at heights of six and eight meters. At six meters, the depth of sliding can occur for up to five to seven meters. Such conditions affect the safety factor value. Analytical results for embankment stability and the safety factor on the condition of soft soil depth of five meters are different when compared with the condition of soft soil depth of ten meters, whereas the results at a depth of ten meters of soft soil to a depth deeper show relatively the same safety factor value.

\section{Number of Geotextile Reinforcement}

The calculations of the required amount of geotextile were done using two different geotextile tensile strengths: $52 \mathrm{kN} / \mathrm{m}$ and $100 \mathrm{kN} / \mathrm{m}$. In accordance with AASHTO standards, the tensile strength of a geotextile used in the design is influenced by the reduction factor. The reduction factor is equal to 1.11.5 due to reduction by installation errors, 2-2.5 due to reduction by creep, 1.1-1.25 due to biotic influence, and 1.1-1.2 due to the influence of chemical reduction.

The reference used in this study is the sliding area that requires the highest amount of geotextile reinforcements. The results show that the slope of the embankment and the depth of the soft soil affect the number of geotextiles required. Soil plasticity also affects the amount of geotextile required. Deeper soft soils require relatively more geotextile reinforcements. However, this conclusion is dependent on the height of the embankment on soft soil. The higher the embankment, the deeper the landslide, which affects the number of geotextiles. At a height of four meters, the number of geotextiles required at a depth of five and ten meters produce the same amount of reinforcement. At embankment heights of six and eight meters, the number of geotextiles required in the soft soil at depths of five and ten meters have slightly different results. In ten meters soft soil depth, the number of geotextile reinforcements will be relatively more. In addition, the greater the soil plasticity, the more geotextile required. An increase number of geotextiles is also obtained the case of in relatively steep embankment slope, namely 1: 1.

To facilitate the comfortable use, the charts of number of geotextile requirements are simplified. The simplification is based on the existing conditions. In addition, the simplification is also carried out for the range of maximum and minimum numbers of geotextile reinforcement requirements based on the size reduction factor used. The results of simplifying the graphs are then verified with the required number of geotextile reinforcements on the embankment roads that have been applied in the field. Relationship graph for the required number of geotextiles is presented in Figure 4. Figure 4 shows the range of required geotextiles according to soil plasticity. The charts have been verified.
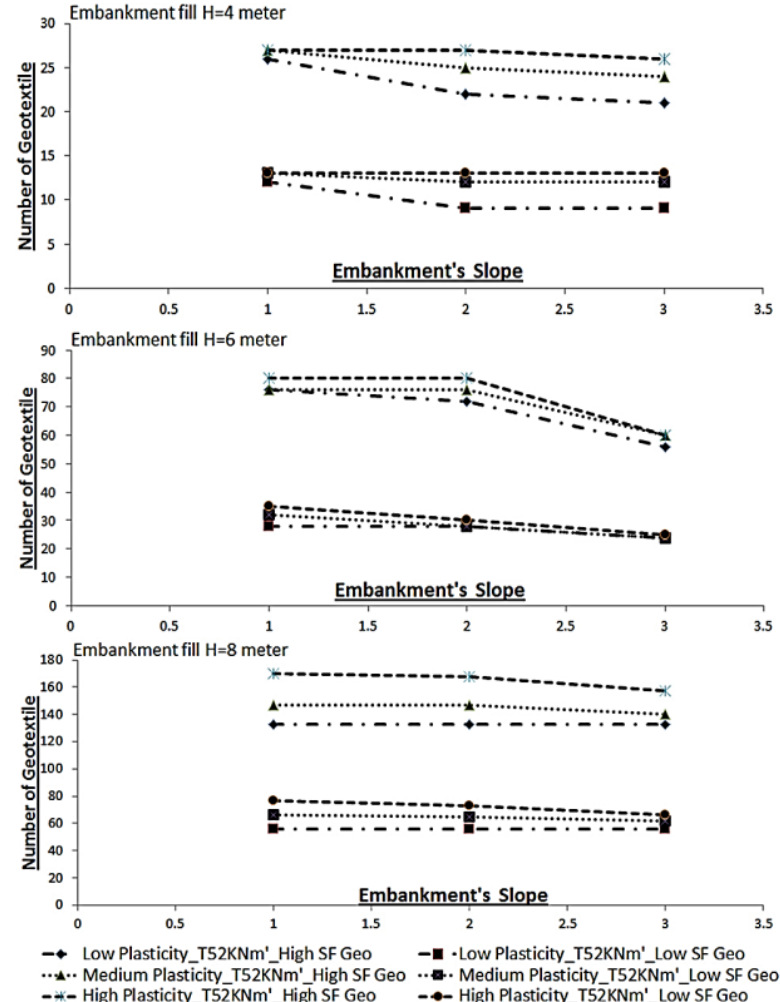

Figure 4a. Suggested Graph of Geotextile Requirements for Various Conditions (Geotextile Ultimete Tensile Strength $($ Tult $)=50 \mathrm{kN} / \mathrm{m}$ )
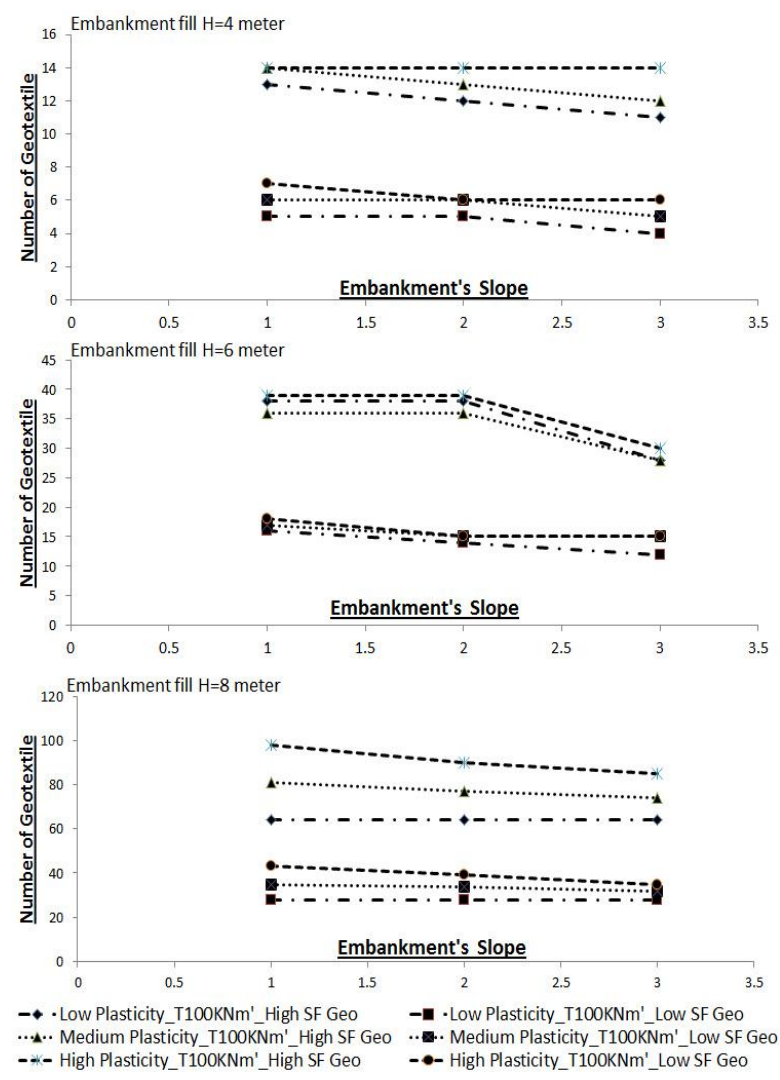

Figure 4b. Suggested Graph Geotextile Requirements for Various Conditions (Geotextile Ultimate Tensile Strength $($ Tult $)=100 \mathrm{kN} / \mathrm{m})$ 
Total requirements for reinforcement geotextiles on the construction of the Ngawi Kertosono toll road is as much as 15 sheets for an embankment height of four meters and 48 sheets for a height of six meters. Determination of geotextile reinforcement is carried on road embankment when the subgrade is not improved by PVD so that the bearing capacity of the subgrade under the embankment does not increase.

\section{Summary and Conclusion}

In this paper, reinforcement requirements for embankments using geotextiles on a variety of soil conditions have been obtained. The analysis yields a graph that indicates the number of geotextiles required under various conditions. Analysis of the graph shows that embankment height, embankment slope, soil type, and the depth of soft soil subgrade contribute significantly to the number of geotextiles requirements. The higher the embankment, the greater the number of required geotextiles; conversely the smaller the slope, the fewer the number of geotextiles required. A greater number of geotextiles are also required where the embankment is on deeper soft soil.

This graph is expected to assist designers in designing reinforcement embankments using geotextile. Total geotextiles on the produced graph are only for those conditions relatively similar to the data used in this study. Therefore, it is still necessary to improve the graph to consider other conditions and to take into account the influence of soil improvement on the number of geotextiles.

\section{References}

1. Crawford, C.B., Fannin, R.J., and Kern, C.B., Embankment Failures at Vernon, British Columbia. Canadian Geotechnical Journal, 32, 1995, pp. 271-284.

2. D’Appolonia, D.J., Lambe, T.W., and Poulos, H.G., Evaluation of Pore Pressures beneath an Embankment, Journal of Soil Mechanics and Foundation Engineering, ASCE, 97, 1971, pp. 881-897.

3. Humphrey, D.N. and Holtz, R.D., Reinforced Embankments - A Review of Case Histories, Geotextiles and Geomembranes, 6(4), 1987, pp. 129-144.

4. Janbu, N., Application of Composite Slip Surface for Stability Analysis, European Conference on Stability of Earth Slopes, Stockholm, 1954.

5. Leroueil, S., Tavenas, F., Mieussens, C., and Peignaud, M., Construction Pore Pressures in Clay Foundations under Embankments, Part
II: Generalized Behaviour, Canadian Geotechnical Journal, 15, 1978, pp. 66-82.

6. Li., A.L. and Rowe, R.K., Effects of Viscous Behavior of Geosynthetic Reinforcement and Foundation Soils on Embankment Performance, Geotextiles and Geomembranes, 26(4), 2008, pp. 317-334.

7. Ortigao, J.A.R., Werneck, M.L.G., and Lacerda, W.A., Embankment Failure on Clay near Rio de Janeiro, Journal of the Geotechnical Engineering Division, ASCE, 109(11), 1983, pp. 1460-1479.

8. Parry, R.H.G. and Wroth, C.P, Shear Stressstrain Properties of Soft Clay, in Soft Clay Engineering, Edited by E.W. Brand, 1981.

9. Rowe, R.K. and Taechakumthorn, C., Combined Effect of PVDs and Reinforcement on Embankments over State-sensitive Soil, Geotextile and Geomembranes, 26(3), 1981, pp. 239249.

10. Bergado, D.T. and Teerawattansuk, C., 2D and 3D Numerical Simulations of Reinforced Embankments on Soft Ground, Geotextiles and Geomembranes, 26(1), 2008, pp. 39-55.

11. Briancon, L. and Villard, P., Design of Geosynthetic Reinforced Platforms Spanning Localized Sinkholes, Geotextiles and Geomembranes, 26(5), 2008, pp. 416-428.

12. Chen, Y-M., Cao, W.-P., and Chen, R.P., An Experimental Investigation of Soil Arching within Basal Reinforced and Unreinforced Piled Embankments, Geotextiles and Geomembranes, 26(2), 2008, pp.164-174.

13. Indraratna, B., Balasubramaniam, A.S., and Balachandran, S., Performance of Test Embankment Constructed to Failure on Soft Marine Clay, Journal of Geotechnical Engineering, ASCE, 118, 1992, pp. 12-33.

14. Loganathan, N., Balasubramaniam, A.S., and Bergado, D.T., Deformation Analysis of Embankments, Journal of Geotechnical Engineering, ASCE, 119, 1993, pp. 1185-1206.

15. Sarsby, R.S., Use of Limited Side Geotextiles (LLGs) for Basal Reinforcement of Embankment Built on Soft Clay, Geotextile and Geomembranes, 25(4-5), 2007, pp. 302-310.

16. Spencer, E., A Method of Analysis of the Stability of Embankments, Assuming Parallel Interslice Forces, Geotechnique, 17, 1967, pp. 11-26.

17. AASHTO, Standard Specifications for Highway Bridges, 16 ${ }^{\text {th }}$ Edition, with 1997 Interims, American Association of State Transportation and Highway Officials, Washington, D.C., 1996.

18. AASHTO, Design Guidelines for Use of Extensible Reinforcements (Geosynthetic) for Mechani- 
Sari, P.T.K. et al. / Proposed Design Graphs of Geotextile Reinforcement/ CED, Vol. 18, No. 2, September 2016, pp. 109-116

cally Stabilized Earth Walls in Permanent Applications, American Association of State Transportation and Highway Officials, Washington, D.C., 1990.
19. GEO-SLOPE International, Ltd., Stability Modeling with SLOPE/W 2007 Version An Engineering Methodology, Third Edition, Canada, 2008. 